\title{
Parenting Efficacy of Married Moms Working with Early Childhood
}

\author{
Ellyn Sugeng Desyanty \\ Faculty of Education, State University of Malang, Indonesia \\ ellynsugeng@fip.um.ac.id
}

\author{
Sri Wahyuni \\ Faculty of Education, State University of Malang, Indonesia \\ sri.wahyuni.fip@um.ac.id
}

\begin{abstract}
The mother working as a parent remains the first figure for early childhood because most of the time the child is with her parents. Homes and parts of homes especially parents become an important part of early childhood life. This research will use phenomenological research methods because it intends to explore the experience felt by working married mothers and interpret every experience of parenting efficacy that emerged during being in the field. The purpose of this study was to describe the parenting efficacy in married mothers working with early childhood. The dimensions of parenting efficacy that appear in the informal self are: (1) the nurture dimension, (2) the health dimension, (3) the discipline dimension, (4) the playing dimension, and (5) the teaching dimension. The emergence of the various dimensions of parenting efficacy is influenced by the following factors: (1) past experiences, (2) culture and community, (3) experience with children, (4) parental knowledge, and (5) social and marital support. The significance of this research is that the informant understands that being a wife has the duty of not only caring for her family members but also helping her partner in finding additional income to support her family's economy. Her role as a mother is to give birth, nurture, and pay attention to her child's growth in various aspects of its development. The dual role that can be done by the informant with the understanding that he is a wife and mother simultaneously.
\end{abstract}

Keywords: parenting efficacy, married mother, working mother

\section{INTRODUCTION}

One of the satisfactions of forming a family is when a husband and a parent become a parent for their children and can see their children developing both physically, emotionally and healthly. Major changes will occur in human life as they become parents. Parenting or in this research is called parenting starting from the process of childbirth, protecting, nurturing, and guiding the children (Martin \& Colbert, 1997). Brooks (2008) mentions parenting is a process of action and interaction between parents and children in which both parties can change each other as children grow up.

Based on Central Bureau of Statistics data in 2013, the number of women employed in East Java province reached approximately 44.8 million people from 93.9 million working people. Mother's working terminology according to Dillaway and Pare (2008) is a mother who works outdoors for 40 hours or more per week and is identified as a career-oriented woman. Mothers work together by having a dual role of motherhood with the primary responsibility of childbirth, raising, and parenting as well as the role of worker (Martin \& Colbert, 1997). Both roles that must be done at once can cause working moms to experience role overload that is the feeling of having various things to do and never enough time to do it all to the end (Bird \& Melville, 1994). Working mothers may also be able to experience role conflict, Martin and Colbert (1997) state that the role conflict experienced by parents when the demands of work collide with the demands of parenting.

Caring competence is a multidimensional construct with a wide range of cognitive, affective, and behavioral components (Coleman \& Karraker, 2000). Parents with strong beliefs about parenting efficacy relate to positive behaviors in parenting (Coleman \& Karrker, 2000). This belief applies as a causal agent in the determination of parenting behavior and child development outcomes (Coleman, 1998). The concept of parenting efficacy is itself a concept based on
Bandura's self-efficacy theory (1989) that is about one's beliefs about their ability to produce a work or action in a particular task or circumstance (Coleman \& Karraker, 2000). Parents with high parenting efficacy were found to be more responsive to the needs of their children (Donovan \& Leavitt, 1985; Unger \& Wandersman, 1985), involvement in direct parenting interactions (Wells-Parker, Miller \& Topping, 1990), and less perceptions of behavioral problems (Johnston \& Mash, 1989). Low parenting efficacy can have an adverse effect especially on parenting behavior patterns for children (Coleman \& Karraker, 2000). In the study of Teti and Gelfand (1991), mothers with low parenting efficacy were skeptical about their ability to deal with temperamental infants and tend to withdraw.

A mother working as a parent remains the first figure for an early child because most of her time should be with her parents. Homes and parts of homes especially parents become an important part of early childhood life. There are many studies that address parenting in the family because of the many issues that develop especially with the working married mother. The possibilities or things that happen plus the study of parenting efficacy that continues to grow to date, researchers are interested to see the parenting experience of the efficacy of married mothers working with young children. This research will use phenomenological research methods because it intends to explore the experience felt by working married mothers and interpret every experience of parenting efficacy that emerged during being in the field. The purpose of this study was to describe the parenting efficacy in married mothers working with early childhood.

\footnotetext{
II. LITERATURE REVIEWS

Parenting

Parenting is the dominant, diverse, and complex domain of the family (June, 1995) known as one of life's important human experiences that can transform a person emotionally, socially, and intellectually (Martin
} 
\& Colbert, 1997). Parenting means acting as a parent in meeting the physical and emotional needs of the child, educating the child to be a competent individual, and taking responsibility for the actions of the child in his or her social environment (Baumrind \& Thomson in Brooks, 2008). Brooks (2008) mentions that parenting is a process of action and interaction between parent and child, both parties can change each other as long as the child grows physically, emotionally and socially.

The role of parents is the most intellectually, emotionally and physically demanding social role of the parents (Coleman \& Karraker in Meunier \& Roskam, 2009). Having a child marks a major transition in a parent's life (Papilia, et all, 2009). Flaherty (in Bornstein, 2002) mentions that there are three role functions of parents who have children, namely: (1) manage (managing) includes activities to organize and arrange resources and activities so that sync between family members with their needs; (2) caretaking parents direct care to a child or family member in need; (3) nurturing parents provide emotional support and love to children and other family members.

There are several factors that can influence parenting, namely differences in parental characteristics, child characteristics, and sociodemographic context (Belsky in Brooks, 2008). Characteristics of parents who influence parenting include personality, developmental history, beliefs, knowledge, gender, abilities, and age. Social context that affects parenting such as socioeconomic status, family structure, work arrangement, social support, and culture. The family structure that affects parenting processes such as the size of the small number of family members, the birth order of children, and complete parent couple at home.

The parenting competence is a multidimensional construct with a wide range of cognitive, affective, and behavioral components (Coleman \& Karraker, 2000). Martin and Colbert (1997) mentioned that one of the characteristics of parents affecting parenting is beliefs. Parental beliefs are important because they will affect the values and behaviors in raising children.

\section{Parenting Efficacy}

Parenting efficacy is a theory based on Bandura's perceived self-efficacy theory of one's beliefs about their ability to produce a work or action in a particular task (Teti \& Gelfand, 1991; Coleman \& Karraker, 2000). Parenting efficacy is an individual belief that parents have about the ability they have in a condition tertenyu (Bandura in Meunir \& Roskam, 2008). Bandura's self-efficacy beliefs (in Saracho \& Spodek, 2005) determine how a person feels something, thinks, and behaves. Bandura (in Jackson \& Scheines, 2005) says people who have high selfefficacy experience less stress and depression because they can act to make their environment more organized and less intimidating. Someone who has low selfefficacy when faced with stress tends to give up easily, making internal attributions a factor of failure, and experienced having anxiety levels or high depression. From this basic theory, in the world of parenting self- efficacy parenting is known as parenting efficacy. Perceptive Bandura parents who feel competent in certain tasks are more likely to get satisfaction from parenting. They have a high level of motivation compared to non-competent parents. This motivation is assumed to improve their parenting skills.

Coleman and Karraker (2000) refer more to the ability of the self as the parent of the mother or what is often called maternal self-efficacy. Grusec, Hastings, \& Mommone (in Naomi, 2002) parenting efficacy is defined as the parental belief in the ability to parenting effectively and produce good child development. Coleman \& Karraker (2000) mentioned that high parenting efficacy is strongly associated with parental capacity to provide stimulation, adaptability and child rearing. Parents with high parenting efficacy were found to be more responsive to the needs of their children (Donovan \& Leavitt, 1985; Unger \& Wandersman, 1985), involvement in direct parenting interaction (Mash \& Johnston, 1985), active parental coping orientations (Wells-Parker, Miller \& Topping, 1990), and little perception of child behavior problems (Johnston \& Mash, 1989). Greater satisfaction is found to predict high parenting efficacy.

Parents feel confident in their parenting abilities in nurturing roles are more likely to show child development (Johnston \& Mash, 1989). This is in line with the study of Bandura (in Coleman, 1998) which shows when individuals have low self-efficacy they will easily emerge emotionally and this condition affects their ability to demonstrate parenting ability effectively. Parents with high parenting efficacy will also be able to discipline children by using appropriate techniques while parents have low parenting efficacy will discipline children by using abusive means such as punishment (Coleman \& Karraker, 2000). Conversely, poor parenting efficacy impacts poorly on parental forms or patterns of behavior toward children (Coleman \& Karraker, 2000). Coleman (1998) mentions low parenting efficacy positively correlated with parent depression (Cutrona \& Troutman, 1986; Teti \& Gelfand, 1991), defensive parental behavior and behavior control (Donovan, 1990), and problems in child behavior (Johnston \& Mash, 1989), parental perceptions of children's difficulties, and passive coping forms in parenting (Wells-Parker, 1990). There are several factors that can affect the parenting efficacy, namely:

\section{Parents Childhood Experiences}

Parents bring an internal representation of their childhood experiences about the dynamics of relationships and attachment to primary caregivers once in their parenting process of parenting (Coleman, 1998). A childhood experience with caregivers that positively parenting behaviors will positively positively parenting opportunities will provide great opportunities for the emergence of parenting efficacy through the vicarious learning process (Leekes \& Crockenberg in Coleman \& Karraker, 2005) that there is a significant relationship between positive memories of past experience small parenting with high parenting efficacy on first experience being a mother

2. Culture and Community 
Cultures and communities provide information about the dominant values of parenting such as views of parenting and child development from experts. Parents who have personal beliefs and behaviors about parenting similar to culture and community tend to have higher parenting efficacy (Coleman \& Karraker, 2005).

3. Experience with Children

Experience with children can affect parenting efficacy of parents. The effects of previous experience with children and higher education on nurturing satisfaction were found to be associated with parenting efficacy (Coleman \& Karraker, 2000). Coleman \& Karraker (2005) also mentioned in his research closeness and daily life with children both children themselves and not found to be associated with parenting efficacy.

\section{Parental Cognitive Factors}

Coleman \& Karraker (2000) found that mothers with higher education and greater incomes had higher parenting efficacy compared to mothers with lower education. Higher educated mothers have a broader knowledge of child development and effective parenting strategies.

\section{Social support and marriage}

Teti (in Coleman \& Carraker, 2000) mentions that parenting efficacy is influenced by the support of individual sociamarital where in a marriage has a strategic position to provide support to his partner and perform his role as a parent. The social support factor of this couple stresses how husbands and wives can provide encouragement, emotional support, and attention to themselves. Mothers who have high levels of parenting efficacy are found in mothers who receive social support and good marital status (Coleman \& Karraker, 2000).

\section{Married Mother Works}

Mother works according to Hoffman and Nye (1984) is the mother who pass an activity to get wages or income. Dillaway and Pare (2008) mentioned that working moms are mothers who work outdoors for 40 hours or more each week and are identified as a woman who has a high career orientation. Hoffman and Nye (1984) mentions several reasons for a mother who chooses to work, namely the need for extra income, working for moms as well as a tool for free time and looking for new experiences, leisure time needs due to boredom and the need to get out of the house, to meet the need for achievement and self-actualization of the mother, as well as the need for a sense of selfcompetence, the recognition, the need to have power and self-satisfaction (Hoffman \& Nye, 1984).

Dillaway and Pare (2008) say that working mothers have to work harder than housewives to become mothers because they physically distant location with their child (home). Mothers work together by having multiple roles of the role of a worker as well as the role of a mother with the primary responsibility of childbearing, raising, and parenting (Martin \& Colbert, 1997). Both the burden must be done at the same time can cause the mother to work experience role overload that is feeling has a lot of things to do and will never enough time to do it all to complete (Bird \& Melville, 1994).

Working mothers may also experience role conflict. Martin and Colbert (1997) role conflict experienced by parents when job demands collide with the demands of parenting. Weber (William, Stacey, Wahlstrom, 2006) suggests that role conflict can cause stress-related problems such as anxiety stimulation, insomnia, headaches, depression, and poor mental health. The burden of working mother becomes lighter with the presence of husband. Mom and dad can share duties and help each other in their respective roles.

Brooks (2008) mentions the amount of time that moms work, the more paternal involvement in the child's physical upbringing. When the father is involved in the child's physical upbringing, the whole family spends more time together. When the mother works, the house can be more enriched and the parent does not use the punishment when the father also plays the role of motherlike parenting (Brooks, 2008).

\section{METHODS}

This research seeks to reveal in depth and examine the characteristics in existence, phenomena and factors that influence the implementation of childcare learning. To be able to uncover these problems in this study used a qualitative approach oriented research focus on the picture of parenting efficacy in married mothers working with early childhood.

This research is a research using qualitative approach with qualitative approach with phenomenological design. Miles and Hubberman (2009) qualitative research is a thorny, in-depth interview, broadly meaningful, concrete, and direct. To get all the phenomena and actual in this research the researcher is an instrument directly in the field and collect the phenomena contained in the situation and dynamics of parenting on working married mother.

Observation technique used in this research is participative observation to obtain data about the behavior of studied subjects and interaction with other components. This is related to Merriam's statement (1998: 7) qualitative research is that it ussually involves fieldwork. The research must physically go to the people, setting, site, institution (the field) in order to observe behavior in its natural setting. Observation is an appropriate technique in this study.

To obtain information directly from research subjects such as reasons, perceptions, expectations and goals, these observations are followed up by direct interviews. Interview is a data gathering technique with a conversation that aims to obtain information about events, activities, organization, feelings, motivation, recognition, and seriousness (Sutopo, 1996). The use of interview techniques is primarily to explore and obtain data that can not or is difficult to trace by observation techniques. The researcher uses a semi-structured interview technique in which the researcher has an interview guide which contains the main issues to be asked but still provides an opportunity for the interviewee to express his feelings, feelings, and ideas. 
This research also uses documentation technique that is taking photo shoot. This technique is used to obtain data that is not netted through observation and interview. Such documentation includes data on the status of the person, the physical condition of the school, the means of infrastructure, and the events related to the research context.

\section{RESULT AND DISCUSSION Picture Parenting Efficacy on Married Moms Working with Early Childhood}

Informant research is a mother who has had an early child who also works as one of the building store employees in the city of Malang. Previously informant worked as an employee at a famous bakery in the city of Malang, choose to move to work due to the health condition of his son who needs attention from him. The informant choosing to work is to help the family economy that currently needs a lot of money to heal his son. The informant chose his current place of work also because only the current place of work that allows him to keep working even though at other times he should ask for permission when accompanying his son to see a doctor or even hospitalization. Daily informant filled with various activities, morning until afternoon the informant became an employee in a building store, at night the informant made small cakes that he would leave to the school canteen in the morning before leaving for work. But in addition to doing work outside the home the informant is still nurturing his son without the help of a nanny, bathing morning, breakfast, cooking for lunch and night is still done alone by informants.

Data obtained in accordance with Martin \& Colbert (1997) opinion that parenting is an important experience in human life that can change a person emotionally, socially, and intellectually. The informant who initially worked on the finance department of a well known bakery in the city of Malang had to choose to quit his place of work and to re-opt to work in a building shop that had a heavier job assignment than the original workplace and a salary that was not as big as those earned the choice is because the informant adjusts to the condition of his son who still needs serious attention. Informants also chose to return to work due to family economic factors that need assistance in fulfilling them. This is consistent with Martin \& Colbert's (1997) statement that the parenting process begins when a person gives birth, guards, nurtures, and develops a child. Parenting is the primary domain in a family that is dynamic, diverse, and complex (June, 1995).

Coleman \& Karraker (2000) argue that parenting efficacy is closely related to parental capacity in providing simulation, adaptive, and child rearing. The results of data that have been obtained during the research took place showed that there are several dimensions of parenting efficacy that appear in the informant, namely:

\section{Parenting Dimensions}

The results of the data analysis found that the informant in the nurture did so with the help of her husband and mother but in the morning treatment the informant still did it himself without the help of others, ranging from bathing in the morning, feeding, cooking dishes and vegetables for breakfast, lunch, and night. This is done before leaving for work. The informant prepares all the needs of his son before leaving for work and always cares for his son upon his return from work in the hope that his son remains in good care and understands the condition of his parents who must leave him to work. The acceptance of the feeling that his son was just left for a while to work so that he did not fuss during his working parents had been prepared informants since his son was a child. The provision and maintenance of emotions in children can be done by receiving feelings, both on their own parents and in children can encourage expressions, emotional states of fear, anxiety, hatred, anger and jealousy among children to parents in a healthier way (Duvall \& Miller , 1985). Parents need to have the competence to be sensitive to the needs of the child, to provide emotional warmth, awareness and interest in the feelings of the child, the ability to express their own feelings, the ability to care for the child attentively, and to encourage freedom for children according to the character and age of the child (Coleman \& Karraker, 1997 ).

2. Health Dimensions

The informant always takes care of his son's health both in terms of eating, and other problems so as not to impede progress. His son who has a medical history to make informants as his mother to prepare care in accordance with the condition of his son. Her son's health is the main focus of the family caring process. The informant always keeps his son's health through his own cooking of all food to be consumed, entrusted to nurturing as long as the informant works to family members who have been trusted to understand the condition of his son. Coming home from the workplace the informant will regain his son again until bedtime arrives. People around the informants' son are also quick and responsive in the health megawasi, if found the health condition of the son of the informant decreased then they will immediately take him to the health service and contact the informant so that the delay in handling the health can be minimized. This is in accordance with the statement Papalia, Old \& Feldman (2009) that one of the tasks of parents is to meet the nutritional needs of children so that children can grow well. Coleman \& Karraker (1997) also states that the competencies parents must have in this dimension are the ability to prepare proper nutrition, timely preventive and corrective health care, detection of signs of disease in children, support proper hygiene maintenance, prevention appropriate injury, encourage children to have adequate sleep time, and encourage children to do outdoor activity.

3. Dimension of Discipline

The results showed that the informant gave some rules to be obeyed by his son, for example eating ice cream may only once a day and eat on time, the rule also applies when his son with others during the informant work. Perform routine activities regularly to familiarize her son perform daily activities and instill discipline in accordance with his condition. The rules 
applied also adjust to the age and character with the aim that his son can grow into a good child and good character. This is in line with what Coleman \& Karaker (1997) states that the competencies parents need in the discipline dimension include the ability to make rules appropriate to the age of the child, have an interest in discipline, feel responsible for child discipline, enforce rules, using techniques appropriate to the child's age, and not harsh in improving children's behavior and having the ability to apply routines in the lives of children.

\section{Dimensional Play}

The results of analytical data that have been carried out show that the DM still give time to socialize to his son well, invites $\mathrm{HN}$ to play at your home when DM has time off, ask for help of his brother's son to invite HN to play with his brother on holidays, and also still allow HN to socialize with others.

$\mathrm{HN}$ still has time to play even though health conditions must always be taken care of, DM always prepares time while he is at home to play with $\mathrm{HN}$ or when he works HN will play with his brothers and friends around his home area. This is in accordance with Hartup's opinion in Bornstein, 2002) that every child has the urge to form and maintain relationships with peers. The task of parents is to facilitate the social needs of children (Papalia, Old, \& Feldman, 2009). According to Coleman \& Karraker (1997) the competencies parents need to have include the ability to manage the interaction of children with peers, facilitate the participation of children in recreational activities, engage in play with children, show interest in children's recreation, provide activities and opportunities appropriate to child development.

5. Teaching Dimension

In the teaching dimension of DM always teaches the child to always do good and independent, the teaching about it is solved with the age and condition of his son HN. The habit of praying and cleaning the toys as the results of data found by DM at any time. Other DM family members also follow what $\mathrm{DM}$ does in familiarizing $\mathrm{HN}$ so that there is no teaching imbalance between DM doing while at home with when DM is not at home. DM never hinders $\mathrm{HN}$ creativity so that $\mathrm{HN}$ can communicate well with others and understand basic understanding about praying, congregational prayer, and how to clean up the game after she finishes playing. Parents have a duty to facilitate children's cognitive development by providing games and reading materials, engaging in child-stimulating cognitive interactions, providing support for child problem-solving skills, and encouraging the creativity of children (Coleman \& Karraker, 1997).

\section{Factors Affecting the Emergence of Parenting} Education in Informant Self

1. Past Parent Experience

DM equips himself to be a parent with past experiences with his parents and also by seeing firsthand how the care activities carried out by his older siblings who had earlier had children. with experience gained DM apply it to the care of his son and modify it according to the conditions that exist in his family.

Each parent carries a representation of his childhood experiences of the dynamics of relationships and attachment to his primary caregiver once into their caring process of parenting (Coleman, 1998). Childhood experiences with caregivers who display positive caring behavior can provide great opportunities for parenting efficacy through the vicarious learning process (Leekes \& Crockenberg in Coleman \& Karraker 2005).

2. Culture and Community

The results obtained that the culture where DM was raised by his parents also contributed to the emergence of parenting efficacy on him. The nurturing that is applied to her son is not only colored by the culture brought in her childhood but also the culture brought by her partner and the community inhabited at the moment. The hope is that his son can grow as children of his age in the environment where his child grows, but in a way that is not separated from DM culture raised and his partner so that when his son lived in any place will also be able to adjust well. Cultures and communities provide information to parents about the dominant values of caring. Parents who have personal beliefs and behaviors about equal parenting with culture and community will tend to have higher parenting efficacy (Coleman \& Karraker, 2005).

3. Experience with Children

Direct experience while being with nephews before DM married and then his experiences while with his son $\mathrm{HN}$ made $\mathrm{HN}$ adjust his parenting pattern. The condition and character of the son becomes the benchmark in choosing the right parenting pattern for his son. Some parenting plans designed by DM have some changes after looking at the condition of $\mathrm{HN}$ and have to change it so that $\mathrm{HN}$ remains comfortable with care done by DM. Experience with previous children and higher education was found to have a relationship in parenting efficacy (Coleman \& Karraker, 2000). The direct experience of a particular behavior is the most powerful source of information in the formation of one's efficacy (Bandura, 1989). So that past experiences with children can influence the development of an individual's parenting efficacy.

4. Parental Knowledge

The data and analysis of the research indicate that the ability to be parents cognitively deliberately grown by DM by always asking good questions to adults around who had earlier had a child as old as HN, mengasn always browsing the internet, and read various books on parenting and child health. It shows that DM has parenting efficacy based on the knowledge it possesses and various ways are still being done to develop its parent ability. Leen \& Karraker (in Coleman \& Karraker, 2005) found that parenting efficacy is associated with several components of cognitive readiness and behavior in parenting, including the selection of positive parenting patterns.

5. Social Support and Marriage

The results of the data obtained during the study indicate that DM obtains social support from both the family and business owners where the place works in 
the care of his son HN. When DM has to work in the morning the care of $\mathrm{HN}$ is entrusted to other family members and keep up with how DM daily takes care of HN. Development of DM's ability to be a parent also gained support from her marriage bond. DM husband is entrusted with care of $\mathrm{HN}$ to DM and always help the care while he was at home to DM not alone or when DM must perform other activities.

Social support and marriage have an important role in the development and maintenance of parenting efficacy (Teti et al in Saracho \& Spodek, 2005). Couples in marriage can provide encouragement and passion and emotional support for their partner in parenting.

\section{The Meaning of Parenting Efficacy Experience Married Mom Working with Early Childhood}

From the previous discussion has been discussed about the dimensions of parenting efficacy and the emergence of parenting efficacy in married mothers working with early childhood in this study in DM a married mother worked in a city of Malang who worked in a building store in the morning and make snacks at at night to help support the husband's income so that the family economy remains well conditioned. Work done DM either in the morning or night does not make DM then replace the care of his son in others, but $\mathrm{DM}$ is still doing kepengasuhan activities of his own son especially daily activities, done at the time before leaving for work in the morning and after he came home from work, only later after her son sleeping DM doing other work at night.

$\mathrm{DM}$ is not alone in caring for her son especially when DM has to work in the morning, some other family members join DM in her nursery activities. But when her son is sick DM can only control himself and her husband in raising his son due to the condition of his son's illness that needs special attention from him.

The discussion on the previous subtitles can be interpreted that working married mothers have a dual role, in which she is not only a wife of someone who must manage finances and help increase income to meet family needs, especially because the son of DM who has a history of diseases that require medical treatment and special attention. Dillaway and Pare (2008) argue that working mothers should work harder than housewives to be mothers because they physically distantly locate their offspring with their children while they are at home. A working mother has a role as a mother with primary responsibility for childbearing, raising, and parenting (Martin \& Colbert, 1997). The workload that must be done at once can cause working moms to experience the role overload that is the feeling of having various things to do and never enough time to do it all to completion (Bird \& Melville, 1994).

Selection of workplace informants who give the opportunity when to take care of children, especially in times of illness can reduce the stress level of married mothers work especially those who have early childhood as the condition of the informant. Role conflict can be experienced by married mothers work when the demands of work collide with the demands of parenting (Martin \& Colbert, 1997). It can be overcome by married mothers working by choosing a workplace that can understand the conditions of demands as a worker and as a mother of their children.

Parenting efficacy can arise with several factors as mentioned in previous subtitles. The emergence of parenting efficacy can arise before a woman marries, for example her past experience, her involvement (experience) with children before marriage. But parenting efficacy can also arise when a married mother has a child and then there are conditions that cause the emergence of parenting efficacy to adjust kepengasuhannya with the condition of children and their partners at this time.

Parenting efficacy is more emerging and evolving as the conditions of marriage and social support around working married mothers. Coleman \& Karraker (2000) states that parenting efficacy is influenced by socialmarital support of an individual. A marriage bond has a strategic position in providing support to his partner so that he can perform his role as a parent.

\section{CONCLUSION}

Informant as married mother working with early child have parenting efficacy. The dimensions of parenting efficacy that appear in the informal self are: (1) the nurture dimension; (2) the health dimension; (3) the discipline dimension; (4) the playing dimension; and (5) the teaching dimension. The emergence of the various dimensions of parenting efficacy is influenced by the following factors: (1) past experiences; (2) culture and community; (3) experience with children; (4) parental knowledge; and (5) social and marital support.

The meaning that emerges from this research is that the informant understands that being a wife has the duty of not only caring for her family members but also helping her partner in finding additional income to support her family's economy. Her role as a mother is to give birth, nurture, and pay attention to her child's growth in various aspects of its development. The dual role that can be done by the informant with the understanding that he is a wife and mother simultaneously.

\section{REFERENCES}

[1] Bird, G. W., \& Melville, K. 1994. Families and Intimate Relationship. New York: McGraw Hill.

[2] Brooks, J. 2008. The Process of Parenting. New York: McGraw Hill.

[3] Bungin, B. 2001. Metodologi Penelitian Sosial: Format-format Kuantitatif dan Kualitatif. Surabaya: Airlangga University Press.

[4] Coleman, P. 1998. Maternal Self-efficacy Beliefs as Predictors of Parenting Competence and Toddlers' Emotional, Social, and Cognitive Development. West Virginia: The Eberly College of Arts and Sciences at West Virginia University.

[5] Coleman, P. \& Karraker, K. 2000. Parenting Selfefficacy among Mothers of School-Age Children: Conceptualization, Measurement, and Correlates. National Council on Family Relations, 49(1), 13-24. 
[6] Creswell, J. W. 2009. Research Design: Qualitative, Quantitative, and Mixed Methods Approaches. California: Sage.

[7] Denzin, N. K \& Lincoln, Y. S. 1987. Strategy of Qualitative Inquiry. New Delhi: Sage.

[8] Dillaway, H. \& Pare, E. 2008. Locatting Mother: How Cultural Debates About Stay-at-home vs Working Mothers Define Women and Home. Journal Family, 29, 437-464.

[9] Martin, C. \& Colbert, K. 1997. Parenting A Life Span Perspective. New York: McGraw Hill.

[10] Milles, M. B. \& Hubberman, A. M. 2009. Analisis Data Kualitatif. Jakarta: Penerbit Universitas Indonesia.

[11] Papilia, O. F. 2009. Life Span Development. New York: McGraw Hill. 